\title{
O PLANO DE ESTUDOS TUTORADOS MINAS 300 ANOS DURANTE A PANDEMIA DE COVID-19: ALGUMAS CONSIDERAÇÕES ${ }^{1}$
}

Márcio Abondanza Vitiello

Vilma Lúcia de Souza ${ }^{3}$

\begin{abstract}
RESUMO: Este trabalho apresenta algumas percepções com respeito à implantação do ensino remoto na rede pública de educação de Minas Gerais por conta da necessidade de distanciamento social ocasionada pela Pandemia de COVID-19. Implantado em maio de 2020, o Plano de Estudos Tutorado (PET) se deu, principalmente, por meio da distribuição de apostilas para suprir as dificuldades de acesso à internet de boa parte dos alunos da educação básica. No trabalho, buscou-se fazer uma análise do componente curricular Geografia nas apostilas do PET edição 300 anos de Minas Gerais, com conteúdo comemorativo ao aniversário do Estado. Infelizmente, essa iniciativa não foi suficiente para equiparar a situação e o nível do ensino público com o ensino privado no país, sinalizando que outras estratégias devem ser implementadas em busca desta meta.
\end{abstract}

PALAVRAS-CHAVE: Ensino Remoto; Materiais didáticos; Ensino de Geografia.

\section{THE PLAN FOR TUTORED STUDIES MINAS 300 YEARS DURING THE COVID-19 PANDEMIC: SOME CONSIDERATIONS}

\begin{abstract}
This paper presents some perceptions regarding the implementation of remote teaching in the public education system in Minas Gerais due to the need for social distance caused by the COVID-19 Pandemic. Implemented in May 2020, the Tutored Study Plan (PET) took place mainly through the distribution of handouts to overcome the difficulties of accessing the internet for a good number of students in basic education. In this article, we sought to analyze the Geography curriculum component in the PET booklets 300 years of Minas Gerais, with content commemorating the anniversary of the State. Unfortunately, this initiative was not enough to match the situation and level of

\footnotetext{
1 Esse artigo é parte do Trabalho de Conclusão de Curso (TCC), intitulado: O plano de estudos tutorados de Minas Gerais durante a Pandemia de Covid-19: algumas considerações, da discente Vilma Lúcia de Souza, sob orientação do Professor Doutor Márcio Abondanza Vitiello, do curso de Licenciatura em Geografia da Universidade Federal de Alfenas (Unifal-MG).

2 Professor Doutor Unifal-MG; márcio.vitiello@unifal-mg.edu.br

${ }^{3}$ Discente Licenciatura Geografia Unifal-MG; vilmaluciadesouza2013@gmail.com
} 
public education with private education in the country, signaling that other strategies must be implemented in pursuit of this goal.

KEYWORDS: Remote Learning; Teaching materials; Teaching Geography.

\section{LE PLAN D'ÉTUDES TUTORIELLES MINAS 300 ANS PENDANT LA PANDÉMIE COVID-19: QUELQUES CONSIDÉRATIONS}

RÉSUMÉ: Ce travail présente certaines perceptions concernant la mise en œuvre de l'enseignement à distance dans le système d'enseignement public du Minas Gerais en raison du besoin de distance sociale causé par la pandémie de COVID-19. Mis en place en mai 2020, le Plan d'Etudes Tutorées (PET) s'est déroulé principalement à travers la distribution de polycopiés pour pallier les difficultés d'accès à internet pour un bon nombre d'élèves de l'enseignement de base. Dans le travail, nous avons cherché à analyser la composante du programme de géographie dans les livrets PET 300 ans de Minas Gerais, avec un contenu commémorant l'anniversaire de l'État. Malheureusement, cette initiative n'a pas été suffisante pour faire correspondre la situation et le niveau de l'enseignement public avec l'enseignement privé dans le pays, signalant que d'autres stratégies doivent être mises en œuvre pour atteindre cet objectif.

MOTS CLÉS: apprentissage à distance ; Matériel pédagogique; Enseignement de la géographie.

\section{INTRODUÇÃO}

A pandemia de COVID-19, iniciada no final de 2019, rompeu barreiras nas esferas sanitária, política, econômica, social e educacional. A partir desse momento, diferentes sociedades passaram a viver um contexto com muitas dificuldades e restrições, precisando se adequar à nova realidade.

Em face de suas especificidades, a educação foi um dos segmentos mais afetado pela conjuntura, enfrentando desafios ímpares que poucos setores da sociedade compartilharam. A atividade escolar e o funcionamento das escolas vivenciaram uma nova realidade que recobrou a implementação de estratégias compatíveis com a manutenção de seu funcionamento.

Os desafios foram gigantescos, recobrando de todos os atores envolvidos um esforço para que fossem superados. Familiares, estudantes e educadores 
conviveram com o inusitado, enfrentando uma realidade sem paralelo para que os prejuízos inerentes à suspensão das atividades presenciais fossem minimizados.

Atentando para isto, neste trabalho, apresentaremos uma análise sobre uma das ações do Governo de Minas Gerais para minimizar os impactos que a pandemia de COVID-19 trouxe para a realidade das escolas públicas estaduais, pois nas mesmas encontram-se alojadas a grande massa estudantil que devido as dificuldades financeiras buscam o ensino gratuito oferecido pelo Estado.

Criteriosamente, este trabalho busca analisar os conteúdos trabalhados em Geografia nas apostilas do Plano de Estudos Tutorados: 300 Anos de Minas Gerais, edição comemorativa ao aniversário do Estado, celebrado em 2020, e distribuídas nas escolas durante a Pandemia.

A análise contempla a estratégia implementada e o conteúdo presente no material distribuído para as escolas levando em conta a conjuntura que obrigou a suspensão dos encontros presenciais e elegeu o ensino remoto como prática necessária para a preservação do ano letivo e garantia de que não haveria suspensão das atividades educacionais no período.

\section{METÓDOS}

Trata-se de uma pesquisa descritiva qualitativa, que promoveu a análise das apostilas do PET 300 Anos de Minas Gerais, como parte da estratégia educacional adotada pelo Estado de Minas em disponibilizar materiais didáticos para a realização do ensino remoto durante a Pandemia.

O material é de responsabilidade da Secretaria Estadual de Educação do Estado de Minas Gerais e foi compartilhado com as escolas da rede pública.

Para a realização da análise nos baseamos em CACETE, PAGANELLI e PONTUSCHKA (2007), para quem os livros didáticos devem ser criteriosamente 
avaliados, levando em consideração, entre outros aspectos: o índice e a estrutura da obra; a presença de imagens, representações gráficas e cartográficas; a linguagem e o uso de diferentes gêneros textuais; as atividades; quem são seus autores e quais são as fontes bibliográficas.

\section{RESULTADOS E DISCUSSÃO}

Com o início da pandemia de COVID-19 no Brasil, as discussões sobre Ensino a Distância (EaD) e ensino remoto receberam maior destaque por parte das instituições educacionais.

Frente à impossibilidade de realização de aulas presenciais, as instituições de educação que atendem aos diferentes níveis de ensino se viram diante de um impasse: suspender as atividades ou mantê-las, na medida do possível, remotamente? Desde então, as perguntas que há tempos inquietam docentes e discentes acerca da EaD passaram a fazer parte das conversas e das reflexões de professores e estudantes que antes tinham como única experiência de educação formal a modalidade presencial (RODRIGUES, 2017, p.26).

Dentre os principais desafios que surgiram incluem-se: suporte tecnológico aos discentes para acompanhamento das atividades remotas; formação continuada dos professores, oferecendo subsídios para o uso das tecnologias; e a interação adequada entre espaço, professores e alunos. Além disso, deve-se destacar alguns obstáculos, como falta de acesso à internet e de uma ambiente favorável para a concentração nos estudos.

A falta de recursos tecnológicos e até mesmo de experiência com o uso pedagógico dos ambientes virtuais de aprendizagem (AVA) se demonstraram um grande entrave, principalmente nas escolas públicas.

A nova realidade social com isolamentos e confinamentos em casa recomendados pelos órgãos oficiais para evitar a disseminação do 
novo coronavírus fez com que o ensino presencial fosse drasticamente privado aos estudantes em seus diversos níveis de ensino (MARQUES, 2020, p. 32).

Essa realidade educacional evidenciou as desigualdades sociais, já que a necessidade do uso de tecnologias para a continuidade das atividades escolares se esbarra em estudantes que não tem acesso à internet e ferramentas digitais para o acesso escolar. Segundo Senhoras (2020):

As famílias com maior escolarização e melhores condições econômicas têm acesso e dão continuidade aos estudos por meio de plataformas estáveis e conteúdos de qualidade em contraposição às famílias com menor escolarização e piores condições econômicas, as quais são estruturalmente ou individualmente limitadas ao acesso ao EAD, e, portanto comprometendo a própria continuidade dos estudos durante (curto prazo) e após a pandemia (médio prazo). (SENHORAS, 2020, p. 134).

Alunos de escolas privadas em sua maioria tem acesso à internet, computadores, notebooks, tablets, celulares e ambientes propícios ao seu desenvolvimento. Enquanto os alunos de escolas públicas, em sua maioria, não possuem aparelhos tecnológicos ou internet de boa qualidade para acompanharem as aulas e atividades virtuais em ambiente adequado para os estudos.

Com todas essas mudanças, gestores das escolas da rede pública no Brasil buscaram por alternativas que se adaptassem ao enfrentamento da nova realidade pedagógica. Em abril de 2020, a Secretaria de Estado da Educação de Minas Gerais (SEE-MG) emitiu a Resolução SEE N4.310, que dispõe sobre normas para a oferta de Regime Especial de Atividades Não Presenciais e institui o Regime Especial de Teletrabalho nas Escolas Estaduais da Rede Pública de Educação Básica e de Educação Profissional, em decorrência da pandemia de Coronavírus (COVID-19), para cumprimento da carga horária mínima exigida. 
Portanto, o Plano de Estudos Tutorado (PET) é instituído exclusivamente para a continuação do calendário escolar de escolas públicas estaduais durante a pandemia:

$\S 1^{\circ} \mathrm{O}$ Plano de Estudos Tutorado (PET) consiste em um instrumento de aprendizagem que visa permitir ao estudante, mesmo fora da unidade escolar, resolver questões e atividades escolares programadas, de forma autoinstrucional, buscar informações sobre os conhecimentos desenvolvidos nos diversos componentes curriculares, de forma tutorada e, possibilitar ainda, o registro e o cômputo da carga horária semanal de atividade escolar vivida pelo estudante, em cada componente curricular (MINAS GERAIS, 2020).

O PET teve a finalidade de orientar e organizar a rotina de estudos de alunos e alunas no momento remoto, oferecendo a eles e elas, semanalmente, atividades diversificadas em cada componente curricular. O PET, para o professor, teve o objetivo de nortear as atividades educativas no ensino remoto, além de direcionar seu diálogo com os estudantes, por meio de diferentes estratégias e mídias.

Em 2020, o PET foi disponibilizado oficialmente em dois canais: no site "Estude em casa" e no aplicativo para dispositivos móveis "Conexão Escola"; e também em material impresso enviado, pela escola, aos estudantes que não possuíssem aparelho celular compatível com o aplicativo Conexão Escola ou que residissem em locais sem internet.

Já o Plano de Estudos Tutorados - 300 Anos de Minas Gerais consiste em um material didático dividido em duas apostilas: uma para o Ensino Fundamental Anos Iniciais ( $1^{\circ}$ ao $5^{\circ}$ ano) e outra destinada ao Ensino Fundamental Anos Finais e Ensino Médio $\left(6^{\circ}\right.$ ao $9^{\circ}$ ano do Ensino Fundamental; $1^{\circ}$ ao $3^{\circ}$ ano do Ensino Médio) para estudantes a partir de 11 anos (Figura 1).

Figura 1 - Capas PET - 300 anos de Minas Gerais 

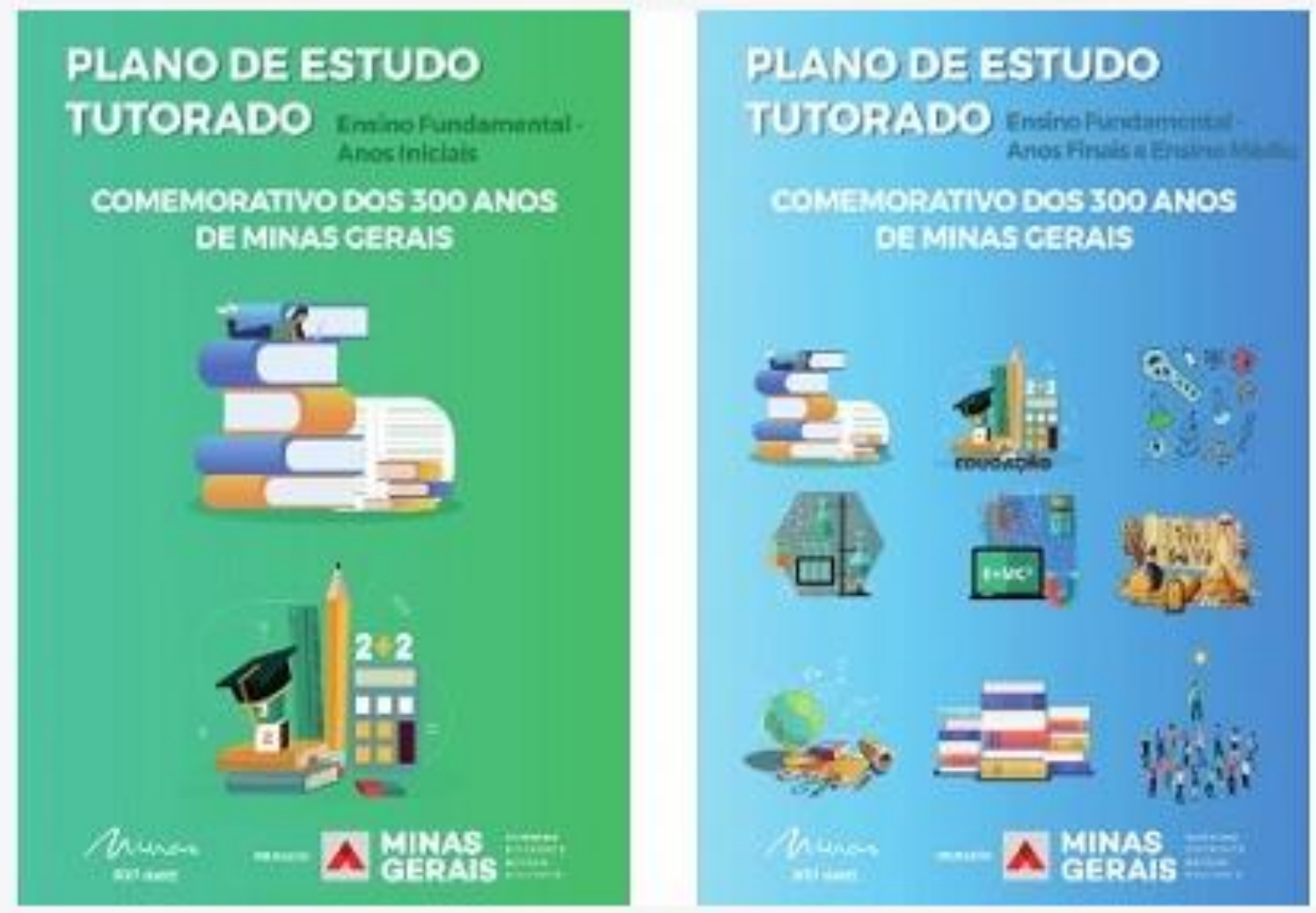

Fonte: Minas Gerais (2020)

O objetivo deste material consiste em subsidiar o ensino-aprendizagem dos alunos da rede pública de ensino e abordar temas vinculados ao estado de Minas. Propor uma construção do conhecimento de forma interdisciplinar e também comemorar os 300 anos de Minas Gerais, efeméride celebrada em dezembro de 2020. Desta forma, a Secretaria de Estado de Educação (SEE) realizou iniciativas com os estudantes da rede pública estadual de ensino para marcar a data.

Em uma primeira análise, buscando identificar a presença dos diferentes componentes curriculares nesses materiais, identificamos que as disciplinas tratadas na primeira apostila eram de língua portuguesa, arte, educação física, língua inglesa, matemática, ciências, geografia, história e ensino religioso.

Já na segunda apostila, dedicada aos anos finais do Ensino Fundamental e Ensino Médio, as competências específicas são da área de linguagem e suas 
tecnologias, área de matemática e suas tecnologias, área de ciências humanas sociais e aplicadas e ciências da natureza.

A apostila PET - 300 anos para o Ensino Fundamental Anos Iniciais possui 53 páginas, que preveem uma carga horária total de 100 horas. O material foi dividido em tópicos distintos, tendo como conteúdos destinados ao ensino de Geografia: ciclo da mineração e o povoamento do estado; curiosidades sobre as regiões da rota do ouro; a bandeira e o brasão de Minas Gerais; principais atividades econômicas; comunidades tradicionais; comunidades indígenas e povos ciganos em Minas Gerais.

A apostila para Ensino Fundamental Anos Finais e Ensino Médio é composta por 41 páginas com carga horária de 100 horas. Os conteúdos disponibilizados na apostila são semelhantes aos encontrados na apostila PET - Ensino Fundamental Anos Iniciais, já que apenas as atividades propostas eram diferentes.

O material foi dividido em tópicos e apresentava como objetivo reconstruir a história de Minas Gerais, identificar os fatos, os tempos que ocorreram e os sujeitos envolvidos; comparar, relacionar e investigar o que mudou e o que permanece até hoje; contar o que já se sabe, o que vem observando no cotidiano; contar com a colaboração dos familiares para relembrar a história de Minas Gerais, principalmente, os costumes e tradições do local.

Os conceitos geográficos trabalhados na apostila PET - Ensino Fundamental Anos Finais e Ensino Médio incluíam curiosidades sobre as regiões da Rota do Ouro; principais atividades econômicas; comunidades tradicionais; comunidades indígenas em Minas Gerais; biografias de personalidades mineiras como Anastácia, Antônio Francisco Lisboa, Clara Nunes e Juscelino Kubitschek de Oliveira.

Sobre a autoria destas apostilas, a Secretaria de Educação de Minas Gerais informa que o mesmo foi construído por um coletivo de professores do ensino público do Estado, e foi uma das ferramentas disponibilizadas para a Rede 
Estadual de Minas Gerais no Regime Especial de Atividades Não Presenciais, contendo questões, atividades propostas e textos problematizadores, sob a gerência da Escola de Formação e Desenvolvimento Profissional e de Educadores seguindo o caráter normativo da Base Nacional Comum Curricular (BNCC).

Quanto à estrutura, nas apostilas PET - 300 Anos não havia um sumário, o que dificultava a localização dos conteúdos e a visualização da organização da obra. No tocante às imagens, a análise que fizemos permitiu constatar a ausência de gráficos ou exercícios cartográficos nas apostilas, deixando uma lacuna no conteúdo geográfico. As representações visuais estavam restritas a imagens de pontos turísticos da Rota do Ouro e cartões postais (Figura 2), porém sem atividades que estimulassem a percepção geográfica e espacial do aluno.

Figura 2 - Cartões Postais presentes na apostila PET - Minas 300 anos

\begin{tabular}{|c|c|c|}
\hline $\begin{array}{c}\text { Os Profetas, obra de Aleijadinho } \\
\text { em Congonhas. } \\
\text { Fonte:https://pixabay.com/pt/photos/ } \\
\text { profetas-aleijadinho-congonha }\end{array}$ & $\begin{array}{r}\text { Casarão antigo- Biblioteca Pú- } \\
\text { blica Municipal Professor Joa- } \\
\text { quim Sepúlveda em Sabará. } \\
\text { Fonte:https://pixabay.com/pt/photos/ } \\
\text { namorados-escultura-minas-gerais }\end{array}$ & $\begin{array}{r}\text { Escultura: Namorados, artigo } \\
\text { de uma loja em Tiradentes. } \\
\text { Fonte:https://pixabay.com/pt/photos/ } \\
\text { namorados-escultura-minas-gerais- }\end{array}$ \\
\hline
\end{tabular}

Fonte: Minas Gerais (2020, p. 21)

A BNCC (BRASIL, 2018, p.359) preconiza, como uma das competências específicas de Geografia, o desenvolvimento do pensamento espacial, fazendo uso das linguagens cartográficas e iconográficas, de diferentes gêneros textuais e das geotecnologias para a resolução de problemas que envolvam informações geográficas. 
Entretanto, identificamos poucos gêneros textuais - como artigos de jornais e revistas, quadrinhos ou poesias - que permitissem o aluno ter contato com linguagens distintas e didáticas que poderiam ampliar seus conhecimentos e capacidades de leitura, não limitando os estudantes a uma única proposta de ensino.

Tal prerrogativa, portanto, é pouco dimensionada no Plano de Estudos Tutorados, Minas 300 anos, já que em relação aos mapas, apenas na Apostila PET - 300 Anos: Anos Iniciais foi encontrado um único mapa do Estado de Minas Gerais e seus territórios de desenvolvimento, com fonte, mas sem data (Figura 3).

Tal fato alerta que a cartografia não foi trabalhada eficientemente nestas apostilas, deixando outra lacuna no conteúdo geográfico. Seria interessante que mapas políticos das diferentes microrregiões; físicos (geomorfologia, geologia, clima, vegetação); de distribuição espacial da população e outros fossem inseridos nas apostilas permitindo uma análise mais aprofundada do espaço geográfico mineiro por professores e alunos.

Figura 3 - Mapa de Minas Gerais presente na apostila PET - Minas 300 anos Anos Iniciais 
Estado de Minas Gerais
Territórios de Desenvolvimento
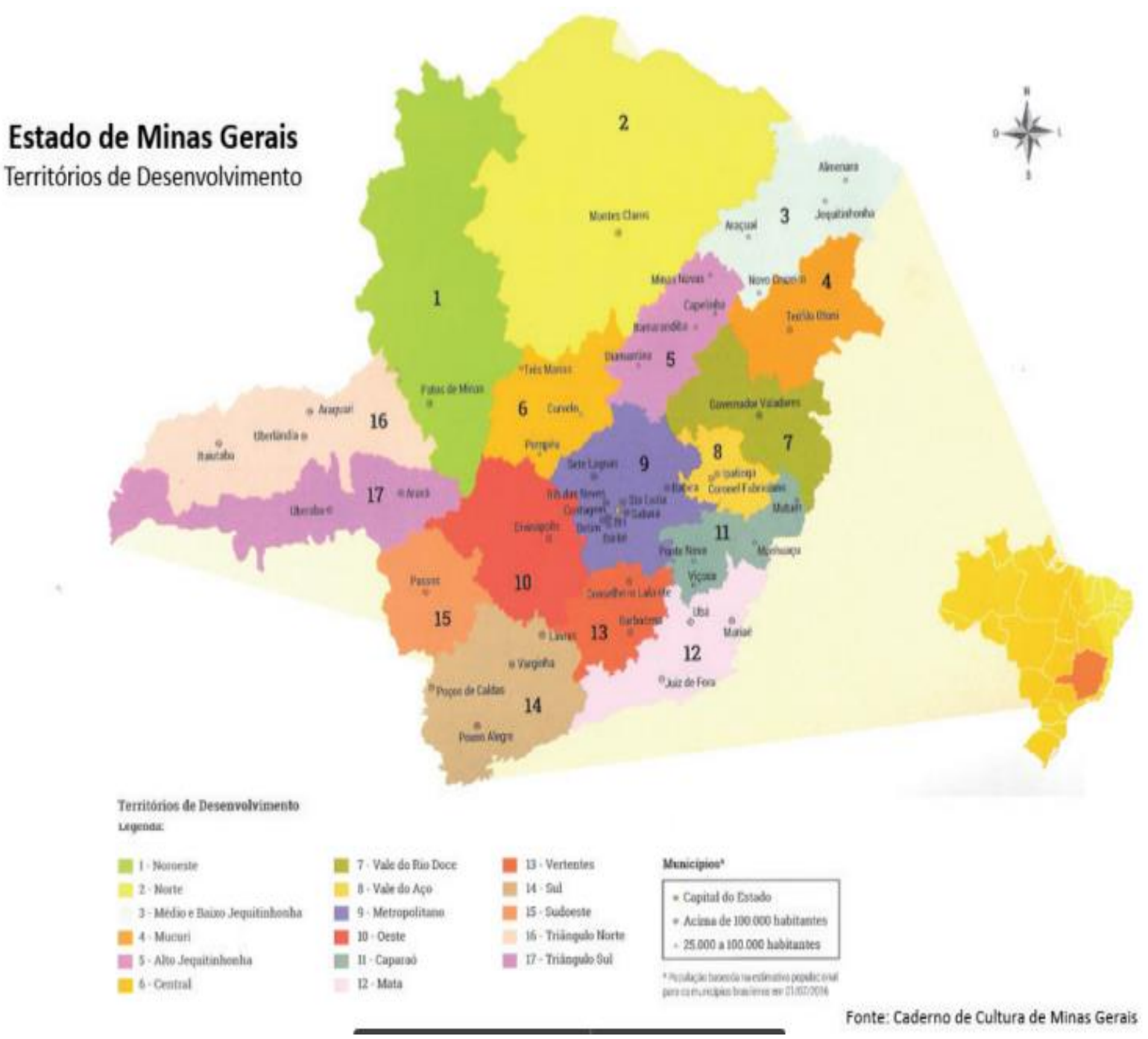

Fonte: Minas Gerais (2020, p. 7)

Dentre as apostilas, não havia a inserção de nenhum gráfico pertinente ao conteúdo da Geografia ou outra disciplina, apenas uma tabela em todo o material (Figura 4). Fato que também poderia ser explorado e auxiliaria os alunos na construção de análises de dados, intepretação de gráficos e ampliação do conhecimento.

Infelizmente o prejuízo causado na ampliação das capacidades interpretativas discentes e na necessária articulação do conteúdo escrito, números e a realidade dinâmica, cobrarão seu preço mais adiante quando os estudantes entrarem em contato com exames de seleção que utilizem esse tipo de recurso para a apresentação de informações que recobrarão resolução. 
Figura 4 - Dados sobre o processo de certificação dos territórios quilombola em Minas Gerais na apostila PET - 300 Anos Minas Gerais - Anos Finais e Ensino Médio

\begin{tabular}{|l|c|}
\hline \multicolumn{2}{|c|}{ Certificação Quilombola } \\
\hline \multicolumn{2}{|c|}{ Ano de referência 2020 } \\
\hline Comunidades certificadas & 311 \\
\hline \multicolumn{1}{|c|}{ Comunidades com processos abertos } \\
\hline Em análise técnica & 07 \\
\hline Aguardando visita técnica & 05 \\
\hline Aguardando complementação de documentos & 16 \\
\hline
\end{tabular}

Fonte: Minas Gerais (2020, p. 9)

Quanto à iconografia, havia algumas fotos de cidades da Rota do Ouro. Entretanto, o tópico é colocado como “Curiosidades sobre as regiões da Rota do

Ouro" (figura 5), mas os textos de apoio tratavam apenas de datas e não curiosidades que despertassem a atenção dos alunos, uma vez que fica disposto um link para acesso de outro material sobre o assunto.

As imagens, embora tenham suas fontes citadas, não são datadas e, nestes casos, poderiam ser maiores, chamativas e com pequenos textos que aguçassem a curiosidade dos leitores.

A proposta teórico-metodológica das apostilas PET - 300 anos de Minas Gerais tem como intuito a valorização da história e da cultura do Estado, perpassando pela realização de práticas pedagógicas. A área de educação das relações étnico-raciais é trabalhada para abranger conhecimentos distintos, promover benefícios nas relações de convívio social na escola, estimulando atividades pedagógicas que são alinhadas à valorização da cultura mineira por 
meio do estudo da formação dos povos tradicionais, viabilizando o cumprimento da Lei $N^{\circ} 10.639 / 2003$.

Em face do mosaico que compõe a rica cultura mineira em suas diferentes regiões, exemplos não são difíceis de serem obtidos para compor o leque de informações disponibilizados para utilização pelos educadores.

Figura 5 - Curiosidades sobre as regiões da Rota do Ouro presentes na apostila PET - Minas 300 anos

Curiosidades sobre as regiōes da Rota do Ouro ...

Mariana
8 de abril de 1711 - criação da Vila do Ribeirão de
Nossa Senhora do Carmo e Albuquerque.
14 de abril 1712 - aprovação por D. João V,
com modificação do nome para Vila de Nossa
Senhora do Carmo.

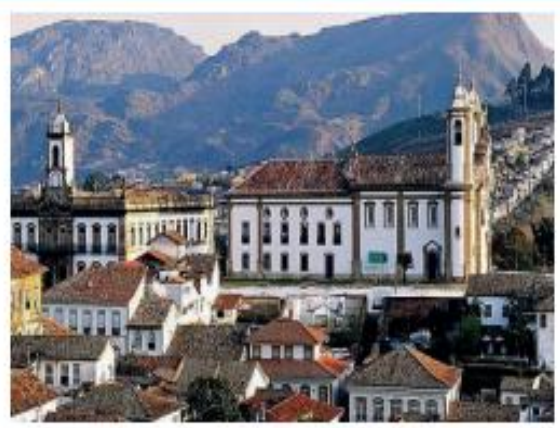

\section{Ouro Preto}

8 de julho de 1711 - criação da Vila Rica de Nossa Senhora do Pilar e Albuquerque.

15 de dezembro de 1712 - aprovação por D. João $V$, com a modificação do nome para Vila Rica de Nossa Senhora do Pilar do Ouro Preto.

Centro histórico da cidade de Ouro Preto

Disponivel em: <https://pt.wikipedia.org/wiki/Ouro_Preto\#/ media/Ficheiros

Fonte: Minas Gerais (2020, p. 3)

As apostilas foram pensadas de maneira que a representatividade da população afro-brasileira e indígena no território mineiro fosse exaltada, tanto 
nas abordagens disciplinares como em textos e materiais selecionados. Dessa forma, esperava-se que a realização dos estudos temáticos integrados pudesse abranger todas as disciplinas, desenvolvendo habilidades e auxiliando na formação integral de cada aluno.

No que diz respeito às atividades propostas da Apostila PET 300 anos para os Anos Iniciais é observado que as propostas são simples, pouco elaboradas e deixam de ser desafiantes aos alunos. A primeira atividade é um caça-palavras (figura 6) e a descoberta do que há em comum entre elas.

Não há uma intenção pedagógica incisiva neste exercício, já que poucas habilidades são exigidas, levando em conta que os alunos poderiam usar o material para construir novas aptidões como a interpretação de textos, o uso de dicionários, a análise espacial e geográfica, críticas e defesas de pontos de vista, construção de textos, pesquisas bibliográficas, entre outros.

Figura 6 - Caça- Palavras da apostila PET-300 anos de MG -Anos Iniciais 
Procure, no caça-palavras a seguir, as palavras relacionadas abaixo do diagrama. Em seguida, faça uma breve pesquisa sobre esses nomes e descubra o que há em comum entre eles:

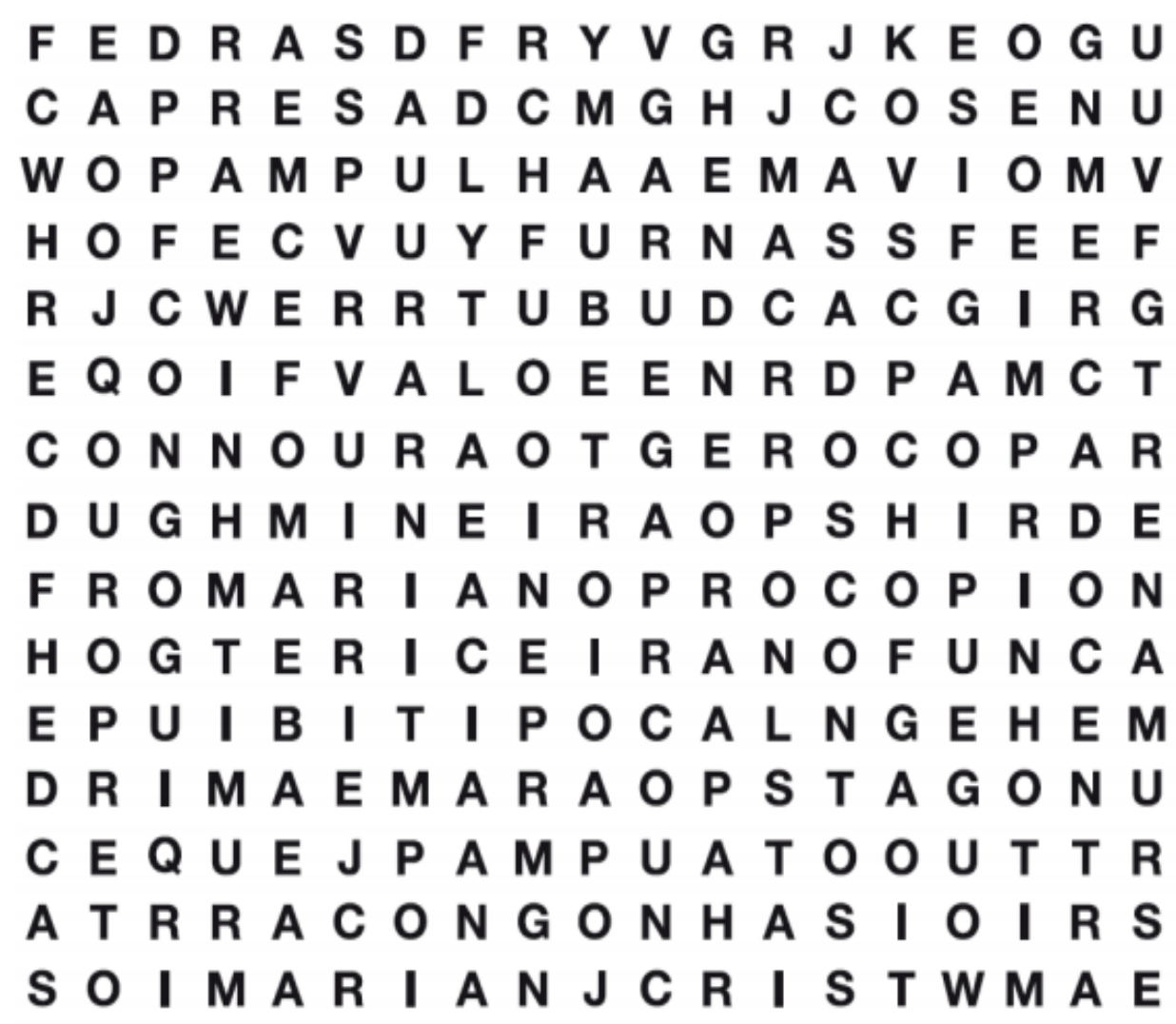

Fonte: Minas Gerais (2020, p. 11)

Todas as imagens e textos estão referenciados. Entretanto, várias fontes vieram de sites não confiáveis como a "Wikipédid" que não tem embasamento conceitual teórico-científico para serem utilizadas em um material de importância educacional. Este fato é preocupante, já que sites dessa origem são duramente criticados pela comunidade escolar e, ainda assim, foram utilizados para compor as apostilas.

Outro fato é que apenas uma referência bibliográfica vem de autores ligados à Geografia como Ângela Maria da Silva Gomes que possui doutorado em Geografia pela Universidade Federal de Minas Gerais (2009). Atualmente é professora no curso de engenharia ambiental e engenharia civil no Centro 
Universitário de Belo Horizonte-UNIBH e coordenou o curso de ecologia do Centro Universitário de Belo Horizonte.

A aprendizagem da Geografia é algo específico e exige autores e referências especializadas na área, desta forma seria necessário que mais autores conhecedores dos temas geográficos de Minas Gerais tivessem participação na construção do material e nas referências bibliográficas utilizadas.

\section{CONSIDERAÇÕES FINAIS}

De maneira geral, o material atende de forma bem limitada aos estudos remotos e as necessidades dos alunos. Para o ensino de Geografia, seria necessário: a inclusão de mapas, exercícios de cartografia, de localização e dimensão espacial. Outra questão seria a inserção de mais gêneros textuais como poemas, poesias, cordéis, textos jornalísticos, quadrinhos e cartoons para que a leitura fosse mais rica, menos cansativa, trabalhando outras linguagens textuais.

A proposição de um Plano de Estudos Tutorados, em meio às dificuldades impostas pela Pandemia, foi uma ação paliativa para tentar minimizar os impactos causados pelo cancelamento das aulas presenciais e pela dificuldade de acesso à internet pela maior parte dos estudantes. No entanto, o conteúdo trabalhado nas apostilas deve ser revisto com calma e especificidades de profissionais de cada disciplina, propondo um material que abranja minimamente os aspectos necessários para o ensino de cada ano, já que seu aspecto marcante é a superficialidade e a desconexão temática.

Após a análise do PET - 300 anos, portanto, pode-se considerar que as apostilas trataram os conteúdos de forma superficial, ampliando o abismo educacional entre as classes sociais, tendo em vista que os alunos das escolas privadas tiveram acesso a métodos e conteúdos mais amplos para o desenvolvimento da aprendizagem durante a Pandemia. 
É importante salientar o fato de que quando as aulas presenciais forem retomadas, todo o conteúdo trabalhado durante este período não será revisto. Não haverá meios de recuperação dos meses de estudos remotos e a defasagem promovida por apostilas tão superficiais marcará o processo de aprendizagem de cada aluno.

Um conteúdo pedagógico destinado ao ensino remoto deveria priorizar a qualidade e minimizar os efeitos dos estudos à distância, oportunizando aos estudantes um ensino que provesse fácil entendimento e um desenvolvimento contínuo de cada um. Na elaboração dos PETs 300 anos houve um custo econômico e temporal que não foi revertido ao que se idealizava em educação remota para estes alunos.

Levando em conta esse contexto de dificuldades em manter os alunos engajados nas aulas remotas, algumas medidas deveriam ser implementadas como parte das políticas educacionais, tais como: melhorar o acesso à internet por meio de subsídios governamentais aos alunos carentes; melhorar a formação continuada de professores para o uso de Ambientes Virtuais de Aprendizagem (AVA); criação de um comitê de professores especialistas para o desenvolvimento dos conteúdos do Programa; orientações gerais aos alunos sobre a execução do período remoto escolar como: estabelecer uma rotina de estudos, estudar nas apostilas PET nos mesmos horários que teriam aula presencial; anotar dúvidas; usar o livro didático como ferramenta de complemento do conteúdo; acompanhar as teleaulas; seguir o planejamento de atividades dos PETS para cada semana; não deixar atividades acumuladas; escolha de um lugar tranquilo para o estudo e respeitar o período de descanso.

Por fim, apesar do esforço do governo estadual em montar uma estratégia em curto prazo para atender as demandas das escolas públicas nesta pandemia, percebemos com esse estudo que tal medida foi insuficiente para diminuir a enorme disparidade existente entre os sistemas público e privado de ensino no 
Brasil. Infelizmente, o cenário Pandêmico ampliou ainda mais o abismo social, reflexos que serão percebidos nos próximos anos, quando essa geração de estudantes das classes populares concluírem precariamente seus estudos.

\section{REFERÊNCIAS BIBLIOGRÁFICAS}

BRASIL. Ministério da Educação. Base Nacional Comum Curricular. Currículo Referência de Minas Gerais. [2018]. Disponível em:

http://basenacionalcomum.mec.gov.br/images/implementacao/curriculos_estad os/documento_curricular_mg.pdf. Acesso em: 17 mar. 2021.

BRASIL. Ministério da Educação. Gabinete do Ministro. Portaria n 343, de 17 de março de 2020. Dispõe sobre a substituição das aulas presenciais por aulas em meios digitais enquanto durar a situação de pandemia do Novo Coronavírus COVID-19. Diário Oficial [da] República Federativa do Brasil: seção 1, Brasília, v. 53, p. 39, 18 mar. 2020b. Disponível em:< https://www.in.gov.br/en/web/dou//portaria-n-343-de-17-de-marco-de-2020-248564376>. Acesso em: 29 jan.2021.

BRASIL. Presidência da República. Lei No 10.639, 9 de janeiro de 2003. Altera a Lei no 9.394, de 20 de dezembro de 1996, que estabelece as diretrizes e bases da educação nacional, para incluir no currículo oficial da Rede de Ensino a obrigatoriedade da temática "História e Cultura Afro-Brasileira", e dá outras providências. Diário Oficial [da] República Federativa do Brasil, Brasília, DF, 9 jan. 2003. Disponível em: http://www.planalto.gov.br/ccivil_03/leis/2003/l10.639.htm. Acesso em: 10 mai. 2021.

CACETE, N. H.; PONTUSCHKA, N. N.; PAGANELLI, T. l; Para ensinar e aprender geografia. São Paulo: Ed. Cortez, 2007.383p.

MARQUES, R. A ressignificação da educação e o processo de ensino e aprendizagem no contexto de pandemia da covid-19. Boletim de Conjuntura (BOCA), Boa Vista, v. 3, n.8, p. 1-8, 2020. Disponível em: http://revista.ufrr.br/boca. Acesso em: 12 fev. 2021.

MINAS GERAIS. Planos de estudos tutorados - Ensino Fundamental anos finais e ensino médio: comemorativo dos 300 anos de Minas Gerais. 2020. Disponível em: https://drive.google.com/file/d/1_baoYaHsN94LfYYL8y1CJb--ajOc3d6f/view. Acesso em 20 fev.2021. 
MINAS GERAIS. Planos de estudos tutorados: Ensino Fundamental anos iniciais: comemorativo dos 300 anos de Minas Gerais. 2020. Disponível em: https://drive.google.com/file/d/1FQWJk7nflQojN7mgJE5zPwCgSZ8Rpi5B/view. Acesso em 20 fev.2021.

RODRIGUES, A. Narrativas digitais, autoria e currículo na formação de professores mediada pelas tecnologias: uma narrativa-tese. 2017. 274 f. Tese (Doutorado em Educação: Currículo) - Pontifícia Universidade Católica de São Paulo, São Paulo, 2017. Disponível em: tede2.pucsp.br/handle/handle/20196. Acesso em: 07 mai. 2021.

SENHORAS, E. M. Coronavírus e educação: análise dos impactos assimétricos. Boletim de Conjuntura (BOCA), Boa Vista, v. 2, n. 5, p. 128-136, 2020. Disponível em: http://revista.ufrr.br/boca. Acesso em: 19 fev. 2021. 